\title{
Egypt Revolution 2.0: Tweets and trends from Egypt
}

\author{
Juby John Eipe \\ Research Scholar,Department of Electronic Media \& Mass Communication, School of Media and \\ Communication, \\ Pondicherry University, Kalapet, Puducherry.
}

\begin{abstract}
Social Media like Twitter were first recognized as a powerful tool in the fight for political transformation at the global level during the Iranian election uprising in 2009, which was successfully muted by the government. These Web 2.0 tools were used effectively in the recent revolution in Egypt with a positive outcome.

This paper tries to analyse the narrative of the struggle for freedom in Egypt as it unfolds through the tweets of the most popular Egyptian Twitter user - Wael Ghonim. The paper proposes to study the units of 'tweets' and 'hashtags' used for trending purposes and the issues discussed, along with their correlation to political events. Tweets from three phases - five days before the Tahrir Square unrest; the period of the unrest till president Hosni Mubarak stepped down and five days after president Hosni's exit from office - were analyzed in the context of Habermas' theories of the role of the public sphere in democratic discourse.

The findings of the study reveal that twitter played a great role in initiating, organising and executing a powerful political movement headed by people with no political background. The trending patterns for the selected hashtags reveal that the selection of familiar words for hashtagging will enable more visibility.
\end{abstract}

Keywords: Digital Media Activism, Public sphere, Twitter, Egypt revolution, Hashtags

\section{Introduction}

Social media shifted the focus of attention from the celebrity in the traditional media to the ordinary citizen - the solitary citizen journalist without any formal journalism training uploading raw data and interacting with peers in the public sphere of Web 2.0. Amateur experiences, videos, photographs and music have never reached so much audience before. This reach translates into the power to influence, and the interactivity of the social networking sites makes the creator or sharer of the information directly accessible for comment thereby increasing a mental proximity to the person and adding credibility to the voice.

Democratic discourses gain great momentum in this public sphere where agendas are set and immediate reaction is available. The widespread generation and consumption of content has created an online space which competes for limited attention of the user community. Gaining attention forms just the first step and when action follows that content, we reach digital media activism. The latest in the series of issues that gained momentum in online spaces and later spilled out to the streets was "Revolution 2.0" in Egypt.

The revolution was triggered by Facebook with the community "We Are All Khaled Saeed" formed in the aftermath of a young Egyptian's beating and death. The group attracted thousands of members worldwide and played a prominent role in spreading and bringing attention to the growing discontent. It soon became a movement calling for protests at the Tharir square in Cairo on January 25, 2011. This had a snowballing effect with the news spreading through social media like twitter.

Twitter made available live and most often accurate information as to what was happening on the ground to the world outside. The protesters used Twitter to organize the event, to update others (sometimes to warn and sometimes to invite). The tweets (as the posts on twitter are called) were re-tweeted (reposted) many times by other users and became the source of firsthand information for the media outside. This is not to say that rumours were not tweeted. But the amount of information generated which was not opinion but just plain factual news stood in stark contrast against the rumours that were spreading.

\section{Review of Literature:}

Sociology's major theoretical traditions emphasize different aspects of electronic media. For Durkheimians, point-to-point communications media like telephones reinforce organic solidarity, while broadcast media like radio or television yield powerful collective representations (Alexander). Marxists focus upon exploitation of communications media to enhance elite control of both politics and production through cultural hegemony and enhanced surveillance (Schiller). Weberians attend to the ways in which point-to-point media advance rationalization by reducing limits of time and space, and broad-cast media provide the elements of distinctive status cultures. Other traditions also offer perspectives on the digital media. Technological 
determinists suggest that structural features of new media induce social change by enabling new forms of communication and cultivating distinctive skills and sensibilities (McLuhan). In the 1960s, students of social change suggested that in the face of new developments in communications technology, industrial society would yield to the "information society," with consequences in every institutional realm (Machlup). Critical theorists problematize the effects of technological change on political deliberation and the integrity of civil society (Habermas). Daniel Bell (34-65) appears to have been the first sociologist to write about the social impact of digital communications media themselves. Bell predicted that major social consequences would derive from two related developments: the invention of miniature electronic and optical circuits capable of speeding the flow of information through networks; and the impending integration of computer pro- cessing and telecommunications into what Harvard's Anthony Oettinger dubbed "compunications" technology. Anticipating the democratization of electronic mail and telefaxing, as well as digital transmission of newspapers and magazines, Bell explored the policy dilemmas these changes would raise, calling "the social organization of the new 'compunications' technology" the most central issue "for the post-industrial society" (1977:38).

Much online public interaction involves participation in virtual communities: cyber-groups based upon people connecting with others who share similar values, interests and concerns in order to exchange information, gain companionship and provide emotional support (Wellman, and Gulia 167-199). Online deliberations have to facilitate rational critical discourse and identify factors inhibiting an extension of such communication to ensure to ensure an ideal public sphere discourse (Dahlberg 615-633). Social network sites are a space where such deliberations could happen.

Social network sites are Web-based services that allow individuals to construct a public or semi-public profile, create a list of others users with whom they share a connection, and view and traverse their list of connections and those made by others within the system (Boyd and Ellison 210-230) Services such as MySpace and Facebook allow people to share favorite TV show lists; new applications introduced in the second half of 2009 enable users to watch streaming videos within the sites. There are also 3D virtual worlds such as Second Life and YouTube3D where users can actually create an avatar and "sit with" other users in a rendered environment to view live multimedia as well. These 3D venues, however, are not mainstream.

Among social network sites, Twitter is a microblogging service launched by a San Francisco-based start-up in 2006 that allows registered users to publish short messages. Twitter poses the question: "What's happening?" and allows users to answer this question, but users do not always post messages that are answers to this question (Before November 2009, Twitter's question was “What are you doing?”).

Long trends in twitter are characterised by the resonating nature of the content rather than number of followers or frequency of posting. (Agarwal et al). Twitter evolves as an effective 'word of mouth' tool for advertising (Huberman et al) and therefore becomes a powerful media tool.

\section{Method:}

The researcher analysed messages on twitter, which are called tweets, posted by the user @ ghonim (Wael Ghonim) who has maximum number of followers among those users who have mentioned their location Egypt. The tweets studied were from January 20 to January 24, 2011 (five days before the Tahrir Square unrest); January 25 to February 11, 2011 (the period of the unrest till president Hosni Mubarak stepped down); February 12 to February 16, 2011 (five days after president Hosni’s exit from office).

The popularity of various trending topics is also compared and a few popular discourses corresponding to the trending patterns were analysed.

In Twitter, users can choose to direct a message at a particular user by adding "@”" in front of the recipient's username (Honeycutt, and Herring 1-10). For instance, if Ramu wanted to respond to a message posted by Balu, the message would be something like: “@Balu I think you're right." The use of “@” however does not indicate that a discussion took place. For instance, Ramu may send Balu a message, but Balu may not respond.

Re-tweets are messages that duplicate a message another person has written. These messages are identified by “RT@ID of original message.” For instance, "RT @sschoolkid I love school” indicates that a user with the ID of "schoolkid" posted "I love school" and that another person is re-posting this message. Re-tweets were treated as being mutually exclusive from "@" messages because the messages are a repeat of the person identified in the message, not directed at the person identified in the message.

Hashtags are words that are preceded with the "\#” sign. Twitter users use hashtags to make searching for relevant topics easier. For instance, using the word "Movement" to search for messages about the Egyptian revolution "Movement" would be a bad search mechanism because the search engine would bring up all messages that included the word "movement." Using "\#Movement" instead of "Movement" enables people to create specific threads of conversation. 


\section{Analysis \\ Wael Ghonim's Tweets}

A twitter user who was bowled over by popularity during the revolution was Wael Ghonim (@ghonim), a Google marketing executive who was detained for his role in organising the revolution on Facebook. An unknown name at the beginning of the revolution, Ghonim commands the support of 117,675 followers as on 16 March 2011.

It was Ghonim who had created the "We Are All Khaled Said" Facebook group which initiated the January 25 movement. Ghonim who was using a pseudonym "El Shaheeed," ("The Martyr" in Arabic) to identify himself went missing to come back after 12 days and revealed his identity.

\section{January 20 - January 25}

Analysing Ghonim's tweets during the first few days of the revolution, one finds that he comes across as a technology expert giving talks on the "power of Internet" in various forums.

The first time he uses the \#jan25 hashtag is on January 25 where he announces his decision to participate in the movement despite warnings from friends and family. The live coverage of the protests starts henceforth. Firsthand accounts of what is happening help in understanding the ground realities and in avoiding rumours.

Ghonim posted twenty two posts on January 25 - the day of the massive protests - narrating in detail the progress of the protests. His posts in Twitter constructed a linear narrative building a coherent story that captured the protest and its increasing severity in detail. He initially calls for people to join the crowd which is hundreds in number trying to break the police siege to go to Tahrir and later we see the swelling of the crowd to tens of thousands of people and the story is spiced with jokes like where he compares protests to "watermelons" and says that he "opened the wrong one".

The posts are very personal in nature and are reflective of the author's views on what he sees around him. He succeeds in conveying very powerful messages with minimum number of words when he says "We broke" (referring to the police siege in Qasr Einy to go to Tahrir) and when he says that the protestors got "brutally beaten up by the police". The first person narrative and the powerful adverbs like "brutally" make a strong impact on the twitter user who is not even from Egypt.

A sense of activism builds up with references to the crowd moving with chants and more references to police brutality charges up the atmosphere. Suspense and tension is built up when he says, "Security police disappeared I feel that something is cooking we are heading to courniche"

He is more like a participant observer who is part of the agitation, involved in the protest and tweeting about what is happening with him and around him observing every development and reporting live.

Ghonim's identity shifts from an individualistic perspective where he says "I made my final decision. I'll attend \#Jan25 Protest." to a collectivistic perspective where he says, "Everyone come to Dar ElHekma security police allow people to join us and we are few hundreds". In between these two personal narrative stages there is an impersonal stage where he displays the factual reporting skills of a journalist ("More than 500 people infront of Dar Elhekma and police surrounding").

\section{January 26 - February 11}

This period sees Ghonim becoming more popular and assertive while his tweets become interactive. He slowly changes into an influential voice and changes his own perceptions on various issues.

Dialogic poly-vocal interactivity is visible in the first post on January 26 where Wael Ghonim thanks people who asked about his whereabouts. This interactivity can be gauged where he later engages in commenting on others' tweets and engages in short debates "(Hey @Gladwell, \#Jan25 proved you wrong. Revolution can be a \#Facebook event that is liked, shared \& tweeted.")

The nationalist spirit of the user comes out where he confesses, "I'm from \#Egypte. I was in the protest today and I want my right to be able to express my opinion on Twitter" where the protest he is referring is the Jan 25 protest. Ghonim shows leadership skills where he says, "Prevented 2 angry guys from throwing a huge metal on police cars from top of the bridge!"

Ghonim who by now has a built up an influential clout for himself talks about his changed perception about police officers ("A lot of them are nice people") showing the first indication that the police is also in a way with the protesters.

An educated 'balanced' and 'mature' individual using abusive language is something that is not quite expected in the linear flow of events. But it happens with Ghonim at one instance where he uses a four letter swearword aimed at the politicians trying to represent the people's movement and take mileage out of it.

The act of re-tweeting begins in this phase where Ghonim re-posts tweets made by users from the actual area of turmoil on issues related to what is happening on the ground. Re-tweets ensure participation of 
more people in discussing this vital issue thereby creating a wider and more vibrant public sphere where exchange of ideas and real-time interactions happen.

Empathy is another quality that is revealed through one of Ghonim's tweets where he says, "Sleeping on the streets of Cairo, trying to feel the pain of millions of my fellow Egyptians."

The issue of discussion moves from the activities on the streets to the issue of Twitter and Facebook being blocked in Egypt and Ghonim uses sarcasm to drive his point as in the tweet "A government that is scared from \#Facebook and \#Twitter should govern a city in Farmville but not a country like \#Egypt \#Jan25" where Farmville is a very popular game on Facebook. In a particular tweet he also asks for information from others regarding the blockage of internet emphasising the interactivity feature of the medium.

From reporting of events in the first phase, Ghonim moves to activism where apart from "dreaming of freedom" he campaigns for freedom of speech urging Egyptians to speak out ("To all Egyptians silence is a crime now!"). He comes a long way from reporting of facts to supporting the need to be "biased towards the people's choice in Egypt"

Ghonim disappears from twitter after a last tweet on 28 January, asking people to "Pray for \#Egypt" and declaring "We are all ready to die" signalling a kind of shift from the assertive tone to a weaker less optimistic one. One later discovers that he went missing for a short while only to return with more posts from 7 February. By then Wael Ghonim has become an icon of the revolution.

The Ghonim who comes back is not highly excited about his freedom and instead is thankful to everyone. In one of the tweets he reveals that he wanted to be remembered by the people during the twelve days while he was jailed. Ghonim continues to be the same kind of person with his emotional remark punning on Google terminology where he says 'Thanks @ Google for all the efforts you did in 'searching' for me. Today 'I'm feeling lucky' that I work for this company."

After the emotional few tweets he returns to his activism mode with more vigour and authority. $\mathrm{He}$ focuses on boosting the morale of the Egyptians ("Dear Egyptians, Failure is not an option")

Ghonim stops directly mobilising people for protests and starts commenting about other mobilising events giving them much credibility ("We are hoping that the "Friday of Martyrs" will be the world largest funeral to bid farewell to 300 Egyptians")

Once again there is shift in identity from the collectivistic perspective to the individualistic one where most of the tweets after gaining his freedom focus on his personal views which are emphasised in a powerful manner. It should be understood that by then Ghonim has evolved from being a part of the crowd to the leader of the crowd. And this change is visible where he tweets "Sorry I don't speak with foreign media about the situation in \#Egypt" and later "I'm honoured to represent 250k Egyptians to 'convey' their demands to the Egyptian Government while collaborating with other activists". The revolution without a particular leader gets a face.

Optimism is built up where he refers to the rain in Cairo as the tears of "Happiness". This poetic allusion or the use of an omen helps the Egyptian 'follower' to be hopeful despite the struggles.

The announcement of the news on Mubarak's exit is in limited words and do not refer to words like "exit", "Flee" etc and instead he tweets, "Mission accomplished. Thanks to all the brave young Egyptians" and "Revolution 2.0: Mission Accomplished".

The rest of the day sees a shift in focus from a feeling of satisfaction towards a "new Egypt" that needs to be shaped up. Western governments are criticized for their support for the Mubarak government. And the credit for the revolution is given to the young Egyptians ("The real hero is the young Egyptians in Tahrir square and the rest of Egypt").

\section{February 12-February 16}

A new phase emerges after the exit of President Hosni Mubarak and Ghonim focuses on addressing the issues and acknowledging key players in the new era. He re-tweets popular politician/Nobel Laureate Mohamed ElBardei and thanks him for being the inspiration for the movement. Ghonim appeals to "all well-educated Egyptians around the world" to "Come back ASAP to build" the nation. He also acknowledges and puts his trust in the Army which stood by the protesters.

More appeals follow as Ghonim grows from an unheard of Google employee to the face of "Revolution 2.0" a powerful political voice to reckon with. He uses his clout to get information ("Urgently I need a final list of all the detainees. Please can someone point me to the most updated list?") and media content from anyone and everyone willing and succeeds to a great extent in focusing people's attention to developing Egypt2.0. Some posts are very personal in nature where he talks about his family.

Ghonim offers a transparent account of nation rebuilding and voices out concerns and needs and motivates the youth of the country to participate by showing them the face of a new Egypt ("Egypt changed, 8 young guys setting with 2 generals from the higher council of the armed forces and freely exchanging our opinions") 
Ghonim's posts are highly emotional and personal at times adding to the power of the message in less than 140 characters.

"We cried a lot. Not because we are weak, we cried because we are human beings.

Our tears were the bullets that killed 30 years of injustice."

The first tweet that Ghonim makes is re-tweeted by just three people and almost instantaneously his popularity increases. 20 re-tweets where he first posts about police brutality and 89 re-tweets for the post in which a highly emotional Ghonim abuses the politicians. The last tweet he makes (January 28) before being jailed is tweeted by more than 100 people.

\section{Hashtags}

The sorting of information with keywords makes recalling of the information fast and effective. These keywords help a computer algorithm to track trending topics or the topics of discussion that are most popular. This in turn helps the user of the public sphere to sift through the large chunk of data available online and to select and respond to only those conversations that one is interested in. The use of hashtags suggests that people want to share their message with a group of people who have the same interest.

Some of the most frequently used hashtags were \#jan25, almost the only hashtag that Wael Ghonim used, \#Egypt, \#Tahrir and \#Cairo. A digital mapping tool called Trendistic (www.trendistic.com) was used to analyse the hashtags and find how they were used world over. It was found that the hashtag \#Egypt was more popular than any other tag at times showing activity of around four percent above the baseline. The next most popular hashtag was \#Jan25 which refers to the date of the huge uprising at the Tahrir square. The hashtags \#Cairo and \#Tahrir overlaps each other. It is also to be noted that these hashtags were not always used in isolation. A combination of tags like \#Egypt \#jan25 \#Tahrir were often used. Such cases could not be statistically analysed due to the limitation of the mapping tool used.



Figure 1: Mapping of hashtags Egypt, Jan25, Cairo and Tahrir.

The hashtag \#jan25 stands out when compared with \#Egypt, \#Tahrir and \#Cairo which refer to places where much of the action is focussed. Tahrir is a place in the capital cirty Cairo of the Arab nation -Egypt. Jan 25 refers to the people's movement and congregation at the Tahrir square on January 25, 2011. \#Jan25 becomes iconic of the revolution and is started to be used even in other contexts around the world including Kashmir.

There is a similarity in the popularity of the four different hashtags where the peaks come almost at the same time. The regular falls in the graph can be attributed to the difference in time zones and the fact that activity is limited when users are offline. It is interesting to note that the graph falls at around 5.00 am GMT regularly after January 28 - in correlation to the time when most of the networked communities are passive.

Activity starts building up around afternoon on 25 January 2011 for the keyword Egypt. Some tweets during this period show us the build up to the massive protests at the Tahrir square with live updates.

SamIDaouD There seems 2 be less police in downtown now, downtown

residents, u can all come down now \# egypt \#25jan

Twitter - Jan 25, 2011 6:02:57 PM

There is a small dip in the graph on 27 January once the mobile networks are blocked along with Twitter and Facebook and later internet too. But users find ways to go around the issue and continue to send tweets via services like Google' Voice to Tweet where people can call an international voicemail number and record their messages which will be posted as tweets online. 
It has to be understood that the trend is not region specific. It is for the entire world. So even when Internet and Mobile networks were shut down, the internet chatter with the keywords mentioned were still active and happening.

The January 25 effect lasts for a few more days and slowly the trend subsides only to resurge on February 10 when rumours of Mubarak's exit from office spread. The excitement subsides quite fast following the realisation that there was no truth in the rumour. The highest peak on the graph is touched on the next day February 11 when Hosni Mubarak actually quits office. The chatter and the excitement slowly subside after a few days.

\section{Conclusion:}

The overwhelming amount of information, opinion and emotions in the form of text, images and videos flowing among users of Twitter gave them an opportunity to be informed firsthand about the developments and participate virtually in the revolution.

This study reveals that twitter played a great role in initiating, organising and executing a powerful political movement headed by people with no political background. The discourse that unveils through Ghonim's tweets proves this fact and also ascertains the power of the common man aided with nothing but technology in creating a new system.

Another vital learning from this paper is that familiarity breeds popularity. The word "Egypt" was more familiar to the ordinary man in another country than "Jan25", "Cairo" or "Tahrir". Therefore the tweets with the tag \#Egypt trends many times more than the other three tags. The learning is to use simple and familiar tags to widen the reach of a message.

It was not the effort of celebrities or politicians that led to the revolution. It was an effort by the common man who used the possibilities of virtual interaction to collate, conspire which spilled out into the real world and vice versa that made Egypt Revolution 2.0.

\section{References:}

[1]. Agarwal, Nitin, Huan Liu, and Philip Tang. "Identifying the Influential Bloggers in a Community." WSDM 2008. 207-217.

[2]. Alexander, Jefrey. Durkheimian Sociology: Cultural Studies. 1988. New York: Cambridge University Press, 1988. Print.

[3]. Bell, daniel. "Teletext and technology: new networks of knowledge and information in postindustrial society." Winding Passage: Essays and Sociological Journeys 1960-1980. . 1980. New York: Basic Books, 1980. 34-65. Print.

[4]. Boyd, Danah, and Nicole Ellison. "Social network sites: Definition, history, and scholarship." Journal of Computer-Mediated Communication. 13.1 (2008): 210-230. Print.

[5]. Dahlberg, Lincoln. "The Internet and Democratic Discourse: Exploring the prospects of online deliberative forums extending the public sphere." Information, Communication and Society. 4.4 (2001): 615-633. Print.

[6]. Habermas, Jürgen. The structural transformation of the public sphere: An inquiry into a category of bourgeois society. 1989. Cambridge MA: MIT Press, 1991. Print.

[7]. Honeycutt, Courtenay, and Susan Herring. "Beyond Microblogging: Conversation and Collaboration via Twitter." 42nd Hawaii International Conference on System Sciences, 2009. 2009. Hawaii: 2009. 1-10. Print.

[8]. Huberman, Bernardo, Romero, Daniel and Wu, Fang. "Social networks that matter: Twitter under the microscope." Arxiv e-prints, December, 0812.1045, 2008. Web

[9]. Machlup, Fritz. The production and distribution of knowledge in the United States. 1962. Princeton: Princeton University Press, 1962. Print.

[10]. McLuhan, Marshall. Understanding Media: The Extensions of Man. 1964. New York: McGraw-Hill, 1967. Print.

[11]. Schiller, Herbert. Information Inequality: The Deepening Social Crisis in America. 1996. New York: Routledge, 1996. Print.

[12]. Wellman, Barry, and Milena Gulia. "Virtual communities as communities: Net surfers don't ride alone." Communities in Cyberspace. Ed. Peter Kollock and Ed. Marc A. Smith. 1999. London: Routledge, 1999. 167-199. Print. 